\title{
Successful intravenous thrombolysis for ischemic stroke after reversal of dabigatran anticoagulation with idarucizumab: a case report
}

\author{
Sergio Agosti ${ }^{*^{*}}$, Laura Casalino ${ }^{2}$, Enrico Rocci ${ }^{3}$, Gabriele Zaccone ${ }^{1}$ and Eugenia Rota ${ }^{3}$
}

\begin{abstract}
Background: Non-vitamin K antagonist oral anticoagulants, including dabigatran, are currently widely used for the prevention of stroke and systemic embolism in patients with non-valvular atrial fibrillation. Recently, idarucizumab, a monoclonal antibody fragment for immediate reversal of dabigatran-induced anticoagulation, has been introduced into the market to be used in life-threatening bleeding or urgent surgery, allowing for rapid normalization of clotting parameters. The use of idarucizumab is not yet well established in patients presenting with acute ischemic stroke on dabigatran who are candidates for thrombolytic therapy.

Case presentation: We report the case of a 71-year-old hypertensive Caucasian woman with non-valvular atrial fibrillation treated with dabigatran $150 \mathrm{mg}$ twice daily, who presented with acute ischemic stroke causing right-sided hemiparesis and aphasia. Two hours after presentation to the emergency department, a decision was made to administer idarucizumab for achieving complete reversal of any potential anticoagulant effect of dabigatran and, in the absence of any contraindications, our patient underwent successful thrombolysis. At discharge, our patient was able to walk unassisted and had only residual aphasia. Twenty days later, she had completely recovered motor function of her right side, with further progressive improvement of aphasia. Repeat cranial computed tomography confirmed the absence of hemorrhage, and anticoagulant therapy with dabigatran $150 \mathrm{mg}$ twice daily was resumed.
\end{abstract}

Conclusions: Our case report adds to the evidence that idarucizumab administration is safe in the setting of patients with atrial fibrillation treated with dabigatran who develop acute ischemic stroke requiring thrombolysis.

Keywords: Dabigatran, Idarucizumab, Ischemic stroke, Non-vitamin K antagonist oral anticoagulants, Thrombolysis

\section{Background}

Non-vitamin K antagonist oral anticoagulants (NOACs) are currently widely used for the prevention of stroke and systemic embolism in patients with non-valvular atrial fibrillation (AF) $[1,2]$, and have been shown to have a more favorable efficacy and safety profile than warfarin [3]. Recently, idarucizumab, a monoclonal antibody fragment for immediate reversal of dabigatraninduced anticoagulation, has been introduced into the market to be used in life-threatening bleeding or urgent

\footnotetext{
* Correspondence: agostisergio@virgilio.it

${ }^{1}$ Cardiology Department, San Giacomo Hospital, Novi Ligure, Alessandria, Italy

Full list of author information is available at the end of the article
}

surgery, allowing for rapid normalization of clotting parameters $[4,5]$. However, use of idarucizumab has not yet been well established in patients presenting with acute ischemic stroke on dabigatran who are candidates for thrombolytic therapy [6]. Indeed, case reports addressing this issue are sparse in the literature [7-10]; therefore, prospective studies are warranted to elucidate the safety and efficacy of idarucizumab in this setting.

The following case report details the use of idarucizumab in a patient who presented with cerebral ischemia while undergoing treatment with dabigatran, and who was a candidate for thrombolytic therapy. We show here that idarucizumab was effective and safe for the immediate reversal of dabigatran-induced anticoagulation, and 
that there were no pharmacodynamic interactions with the thrombolytic therapy.

\section{Case presentation}

A 71-year-old obese Caucasian woman $(100 \mathrm{~kg}$, body mass index $33 \mathrm{~kg} / \mathrm{m}^{2}$ ) presented to the emergency department at 08:30 p.m. with motor aphasia, ideomotor apraxia, and right facio-brachio-crural hemiparesis that had occurred 1 hour before admission; her National Institutes of Health Stroke Scale (NIHSS) score was 9. She had no other neurological symptoms.

Our patient was fully self-sufficient and retired; she had previously worked as a secretary. She had a history of hypertension dating back to around 15 years and she was on antihypertensive therapy with candesartan (16 mg once daily) and furosemide ( $25 \mathrm{mg}$ on alternate days). She suffered from paroxysmal AF diagnosed in 2014, and, at presentation, was on sotalol $80 \mathrm{mg}$ three times daily. In November 2015, she was put on oral anticoagulant therapy with warfarin, replaced by dabigatran 150 twice daily in October 2016. Her medical history included thyroid disease in 1987, prior bilateral total hip replacement surgery in 2013, an episode of pulmonary embolism in November 2015, and mild obstructive sleep apnea syndrome.

On admission, her blood pressure was $130 / 80 \mathrm{mmHg}$ and oxygen saturation $\left(\mathrm{SaO}_{2}\right)$ was $98 \%$. An electrocardiogram (ECG) revealed a normal sinus rhythm with a heart rate of $55 \mathrm{bpm}$. One week previously, our patient had undergone a cardiology evaluation, and electrical cardioversion of persistent AF was planned.

Urgent brain imaging with computed tomography (CT) did not reveal any ischemic lesions.

Initial blood testing was unremarkable, with a hemoglobin level of 14.4 g/dL (normal range: $12-16 \mathrm{~g} / \mathrm{dL}$ ), and normal renal function with a creatinine level $0.79 \mathrm{mg} / \mathrm{dL}(0.51-0.95 \mathrm{mg} / \mathrm{dL})$ and a creatinine clearance of $103 \mathrm{~mL} / \mathrm{min}$. Her cardiac troponin level was $0.01 \mathrm{ng} / \mathrm{mL}(0.00-0.4 \mathrm{ng} / \mathrm{L})$ and her coagulation panel revealed an activated partial thromboplastin time (aPTT) of 29 seconds (20-29.6 seconds) with an international normalized ratio (INR) of $1.31(0.8-1.30)$.

After family and personal history-taking, it was uncertain whether our patient had been compliant with her prescribed dose of dabigatran.

At 11:00 p.m., a decision was made to administer intravenous idarucizumab $(2 \times 2.5 \mathrm{~g} / 50 \mathrm{~mL})$ to achieve complete reversal of any potential anticoagulant effect of dabigatran. In the absence of contraindications, our patient received thrombolytic therapy with tissue plasminogen activator intravenously at $0.9 \mathrm{mg} / \mathrm{kg}$ body weight according to standard protocol (total dose $90 \mathrm{mg}$ infused over 60 minutes, with $10 \%$ of the total dose administered as an initial bolus over 1 minute).
Our patient improved rapidly after thrombolysis and had only minor right hemiparesis with mild improvement of aphasic symptoms within a few days.

Serial brain CT scans performed in the following days showed ischemic hypodensity involving the left Sylvian fissure (Fig. 1).

During hospitalization, our patient had an episode of atrial tachyarrhythmia appropriately managed with amiodarone intravenously and oral bisoprolol. She was placed on combination therapy with aspirin $(100 \mathrm{mg})$ and low-molecular-weight heparin (4000 IU twice daily). Doppler imaging of the supra-aortic trunks and echocardiography studies did not show any abnormalities.

At discharge, our patient was able to walk unassisted and had only residual aphasia and a regular ventricular response to AF. She was prescribed aspirin (100 mg daily), bisoprolol (2.5 mg twice daily), ranitidine (150 mg daily), and low-molecular-weight heparin (4000 IU twice daily).

Twenty days after discharge, our patient had completely recovered motor function of her right side, with further progressive improvement of aphasia. A repeat cranial CT scan confirmed the absence of hemorrhage, and anticoagulant therapy with dabigatran $150 \mathrm{mg}$ twice daily was resumed. One week later, her dabigatran plasma levels obtained 2 hours after ingestion were $294 \mathrm{ng} / \mathrm{mL}$ (normal range $>30 \mathrm{ng} / \mathrm{mL}$ ) with an aPTT of 47 seconds.

At 6 months follow-up, our patient had complete functional motor recovery, with persistent but mild expressive aphasia; she was still on therapy with dabigatran $150 \mathrm{mg}$ twice daily.

\section{Discussion}

Evidence derived from numerous clinical trials has consistently demonstrated a good safety profile for NOACs, with a relative risk reduction in intracranial hemorrhage of up to $60 \%$ [11], even though the management of NOAC-related bleeding still remains a significant challenge in clinical practice [12]. The recent approval of idarucizumab, a monoclonal antibody fragment specifically

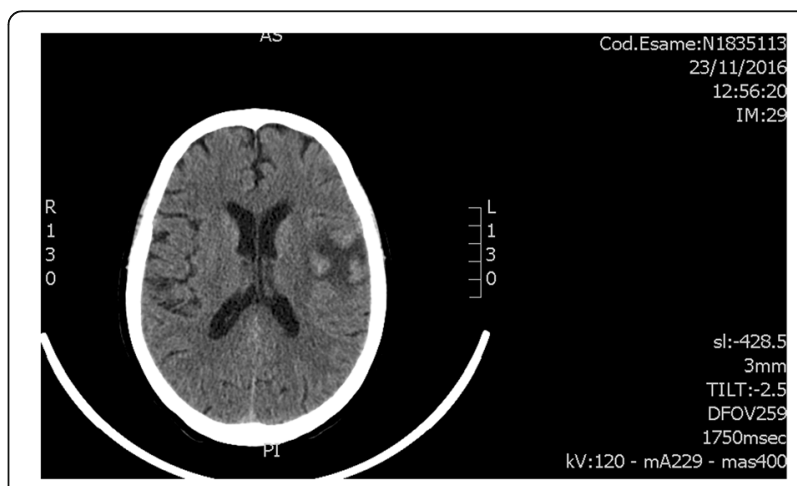

Fig. 1 Ischemic hypodensity involving the left Sylvian fissure on brain computed tomography 
targeted to reverse the direct thrombin inhibitor dabigatran, has provided the medical community with an important tool for the management of patients with uncontrolled bleeding.

The REVERSE-AD study enrolled patients treated with dabigatran who presented to the emergency department with life-threatening bleeding, or who required urgent surgery or intervention. Idarucizumab completely reversed the anticoagulant effect of dabigatran within minutes in both patients groups, suggesting that this antidote is safe and effective [4].

Several case reports also demonstrated the efficacy of idarucizumab in specific clinical settings, including patients with acute ischemic stroke eligible for thrombolysis [13]. Intravenous thrombolytic therapy is contraindicated in anticoagulated patients, and the availability of an effective means to ensure rapid restoration of hemostasis seems to further improve the chances of a successful recanalization of occluded vessels in the acute phase of an ischemic stroke $[14,15]$.

Our patient could not remember whether she had been compliant with her prescribed dose of dabigatran. While values of aPTT in the normal range appeared to confirm the possibility of noncompliance, further investigations (for example, counting remaining pills or questioning family members) were not undertaken because of the narrow time window for intravenous thrombolysis. However, aPTT provides only a qualitative measure of the anticoagulation status and does not have a linear relationship with dabigatran plasma concentration. Therefore, administration of idarucizumab prior to thrombolysis was deemed opportune [16].

Because of NOACs' short half-life (approximately 12 hours), even one missed dose may lead to subtherapeutic anticoagulation, exposing patients to an increased risk of systemic thromboembolism and intracranial hemorrhage. Therefore, compliance and adherence to treatment is crucial. We assumed that our patient had been noncompliant with her prescribed dose of dabigatran, which may well account for the occurrence of ischemic stroke, and we decided to resume dabigatran administration after 3 weeks in the absence of any findings suggestive of lack of efficacy.

Seven days after resumption of therapy, assessment of dabigatran plasma concentrations and routine coagulation parameters confirmed an effective return of anticoagulant activity following regular intake of the medication and, therefore, the therapy could be continued safely.

Compared with other published cases, this clinical case report is relevant in that idarucizumab was given under conditions in which dabigatran was only partially effective, and therefore had a less-than-optimal anticoagulant profile. Despite this, idarucizumab did not show a prothrombotic effect, and there were no pharmacodynamic interactions with the thrombolytic therapy.

\section{Conclusions}

In situations of life-threatening bleeding or urgent surgery, the immediate reversal of dabigatran-induced anticoagulation by idarucizumab can rapidly normalize clotting parameters and avoid morbidity. Our case report adds to the evidence that idarucizumab administration is safe in the setting of AF patients treated with dabigatran who develop acute ischemic stroke requiring thrombolysis, although further prospective studies are warranted to define the optimal management strategy for these patients [17].

\section{Abbreviations}

AF: Atrial fibrillation; aPTT: Activated partial thromboplastin time; CT: Computed tomography; ECG: Electrocardiogram; INR: International normalized ratio; NIHSS: National Institutes of Health Stroke Scale; NOACs: Non-vitamin K antagonist oral anticoagulants; $\mathrm{SaO}_{2}$ : Oxygen saturation

\section{Acknowledgements}

We thank Gayle Robins and Melanie Gatt, independent medical writers, who provided editorial assistance and journal styling services prior to submission on behalf of Springer Healthcare Communications. Editorial services were funded by Boehringer Ingelheim.

Funding

No funding was received for this study.

Availability of data and materials

All data generated or analyzed during this study are included in this published article.

Authors' contributions

ER was the physician who handled the case, SA was a major contributor in writing the manuscript. All authors read and approved the final manuscript.

Ethics approval and consent to participate

Not applicable.

Consent for publication

Written informed consent was obtained from the patient for publication of this case report and any accompanying images. A copy of the written consent is available for review by the Editor-in-Chief of this journal.

\section{Competing interests}

SA has received speaker honoraria from Boehringer Ingelheim, Pfizer, Bayer, Bristol-Myers Squibb, and Daiichi Sankyo. LC has received speaker honoraria from Boehringer Ingelheim, Pfizer, and Bristol-Myers Squibb. GZ has received a speaker honorarium from Boehringer Ingelheim, and Bayer. ER and ER declare that they have no conflict of interest.

\section{Publisher's Note}

Springer Nature remains neutral with regard to jurisdictional claims in published maps and institutional affiliations.

\section{Author details}

${ }^{1}$ Cardiology Department, San Giacomo Hospital, Novi Ligure, Alessandria, Italy. ${ }^{2}$ Cardiology Unit, ASL 3, Genoa, Italy. ${ }^{3}$ Neurology Unit, San Giacomo Hospital, Novi Ligure, Alessandria, Italy.

Received: 21 April 2017 Accepted: 21 July 2017

Published online: 15 August 2017

\section{References}

1. Garber JL, Willenborg KL, Rose AE. Analysis of anticoagulant prescribing in non-valvular atrial fibrillation and development of a clinical tool for guiding anticoagulant selection. J Thromb Thrombolysis. 2015;40:248-54. 
2. Kumar S, Danik SB, Altman RK, Barrett CD, Lip GY, Chatterjee S, et al. Non-vitamin $\mathrm{K}$ antagonist oral anticoagulants and antiplatelet therapy for stroke prevention in patients with atrial fibrillation: a meta-analysis of randomized controlled trials. Cardiol Rev. 2016:24:218-23.

3. Connolly SJ, Ezekowitz MD, Yusuf S, Eikelboom J, Oldgren J, Parekh A, et al. RE-LY Steering Committee and Investigators. Dabigatran versus warfarin in patients with atrial fibrillation. N Engl J Med. 2009;361:1139-51.

4. Pollack Jr CV, Reilly PA, Eikelboom J, Glund S, Verhamme P, Bernstein RA, et al. Idarucizumab for dabigatran reversal. N Engl J Med. 2015;373:511-20.

5. Ansell JE. Reversing the effect of oral anticoagulant drugs: established and newer options. Am J Cardiovasc Drugs. 2016;16:163-70.

6. Turine G, Peeters A, Hermans C, Eeckhoudt S, Duprez T. Intravenous thrombolysis after reversal of dabigatran by idarucizumab: a moment to be a pioneer. Acta Neurol Belg. 2017; doi:10.1007/s13760-017-0751-5 [Epub ahead of print].

7. Schäfer N, Müller A, Wüllner U. Systemic thrombolysis for ischemic stroke after antagonizing dabigatran with idarucizumab - a case report. J Stroke Cerebrovasc Dis. 2016;25:e126-7.

8. Kafke W, Kraft P. Intravenous thrombolysis after reversal of dabigatran by idarucizumab: a case report. Case Rep Neurol. 2016;8:140-4.

9. Gawehn A, Ayari Y, Heuschkel C, Kaste M, Kermer P. Successful thrombolysis with recombinant tissue plasminogen activator after antagonizing dabigatran by idarucizumab: a case report. J Med Case Rep. 2016:10:269.

10. Mutzenbach JS, Pikija S, Otto F, Halwachs U, Weymayr F, Sellner J. Intravenous thrombolysis in acute ischemic stroke after dabigatran reversal with idarucizumab - a case report. Ann Clin Transl Neurol. 2016;3:889-92.

11. Grysiewicz R, Gorelick PB. Incidence, mortality, and risk factors for oral anticoagulant-associated intracranial hemorrhage in patients with atrial fibrillation. J Stroke Cerebrovasc Dis. 2014;23:2479-88.

12. Balla S, Koerber S, Flaker G. Management of bleeding in patients receiving non-vitamin K antagonists. Postgrad Med J. 2017;93:221-5.

13. Diener HC, Bernstein R, Butcher K, Campbell B, Cloud G, Davalos A, et al. Thrombolysis and thrombectomy in patients treated with dabigatran with acute ischemic stroke: expert opinion. Int I Stroke. 2017:12:9-12

14. Schulz JG, Kreps B. Idarucizumab elimination of dabigatran minutes before systemic thrombolysis in acute ischemic stroke. J Neurol Sci. 2016;370:44

15. Ng FC, Bice J, Rodda A, Lee-Archer M, Crompton DE. Adverse clinical outcomes after dabigatran reversal with idarucizumab to facilitate acute stroke thrombolysis. J Neurol. 2017;264(3):591-4.

16. Conway SE, Hwang AY, Ponte CD, Gums JG. Laboratory and clinical monitoring of direct acting oral anticoagulants: what clinicians need to know. Pharmacotherapy. 2017;37:236-48.

17. Husted S, Verheugt FW, Comuth WJ. Reversal strategies for NOACs: state of development, possible clinical applications and future perspectives. Drug Saf. 2016;39:5-13.

\section{Submit your next manuscript to BioMed Centra and we will help you at every step:}

- We accept pre-submission inquiries

- Our selector tool helps you to find the most relevant journal

- We provide round the clock customer support

- Convenient online submission

- Thorough peer review

- Inclusion in PubMed and all major indexing services

- Maximum visibility for your research

Submit your manuscript at www.biomedcentral.com/submit

) Biomed Central 